\title{
Midwife's uniform from Tsan Yuk Hospital
}

\author{
Harry YJ Wu, MD, DPhil \\ Medical Ethics and Humanities Unit, Li Ka Shing Faculty of Medicine, The University of Hong Kong, Hong Kong
}

https://doi.org/10.12809/hkmj-hkmms202104

Midwives wearing green uniforms have disappeared from sight in Hong Kong alongside the transformation of this once thriving vocation. In 1906, with the emergence of modern midwives who were trained in the Western style, the practice of Chinese traditional midwives, known as wanpo (穩婆), began to be phased out. It is generally perceived that modern midwifery successfully shifted the place for delivery from homes to hospitals. The century-long struggle for the autonomy of the nursing profession embodies the heterotopic space in the port city, where cultural tradition and new medical sciences develop concurrently as "frenemies", and where the two keep contradicting and transforming each other.

The birth of midwifery as a profession necessitated the formation of a statutory body to monitor the registration, training, and services of the new professional practice. In 1902, the Midwives Act provided a framework for regulation of midwifery in Britain. The Act made certification a requirement for practitioners, and those who practised illegally would be liable to penalty. At that time, it was already assumed that medical science in Hong Kong was advanced enough to train Chinese midwives. In 1910, the Hong Kong Midwives Board was established under the auspices of the Midwives Registration Ordinance No. 22. ${ }^{1}$ At that time, 2 years after the promulgation of such ordinance, women could no longer deliver babies unless they were certified by the Board. ${ }^{2}$ Over the next decade, midwifery practice remained very similar to wanpo traditional services; however, their accreditation was all conducted by physicians.

In 1903, Alice Memorial Hospital appointed Alice Sibree as the Lady Doctor, in order to train young Chinese women as midwives. However, Sibree's continuing difficult relationship with then Medical Superintendent, Robert McLean Gibson, resulted in her early resignation. ${ }^{3}$ Nevertheless, during that time, more than a thousand babies were born with the modern midwifery method. In 1922, under the new registration regulation, Tsan Yuk Hospital became the first institution to systematically provide maternity services and to train Chinese midwives. ${ }^{4}$ Very soon, Tung Wah Hospital, established in the 1870 s to meet the needs of the local Chinese population, also began Western midwifery training. In the 1930s, private hospitals, such as the Hong Kong Sanatorium and Hospital, joined the effort to train midwives. The teachers were obstetricians and senior midwifery sisters on maternity wards. Even midwives who continued to provide home visiting services were mostly affiliated with a hospital.

In Hong Kong, implementation of health policies often fell short of societal demands. In the 1930s, a ban on traditional wanpo against the backdrop of population growth did not meet the needs of the population. Therefore, wanpo continued to advertise their services in newspapers. The colonial government did not heavily punish such practice, $^{5}$ and ultimately had to relax the criteria for midwife registration, allowing wanpo who had practised for more than 2 years to become midwives. ${ }^{6}$ Nevertheless, training was necessary to reduce infection rate and unnecessary death. ${ }^{7}$ After World War II, midwives earned the reputation of a learned professional community just when the vocation peaked and then began a gradual decline. During the first two decades after the war, demand for delivery services expanded-deliveries we now know as the baby boomer generation. However, after obstetrics and gynaecology became a recognised specialty, and soon physicians took over caring for women through pregnancy and childbirth. Then, from 1970 onwards, Hong Kong began to see declining birth rates. Lifetime live births per thousand women were $>3400$ in 1971 but decreased to only about 1000 in $2007 .{ }^{8}$ In the 1990 s, midwifery training schools began to close.

The uniforms worn by midwives in Hong Kong over the years are a testament to the evolution of fashion codes. As a pioneering group of working women in the colony, they were never late to catch up with styles popular in modern Chinese cities. In the 1920s, midwives in Hong Kong wore cheongsams similar to those worn by Chinese socialites and upper-class ladies in Shanghai at the time. The green cotton uniform shown here is a Western-style working garment (Fig). This type of uniform was worn by midwives in government service between the 1970s and 1990s as they went about their routine work. The letters 'TYH' and number 45 stitched on the garment stand for 'Tsan Yuk Hospital', indicating the affiliation of the owner. The name of the owner, Ho Fung-chan (何鳳珍), is stitched below this. According to the Government 


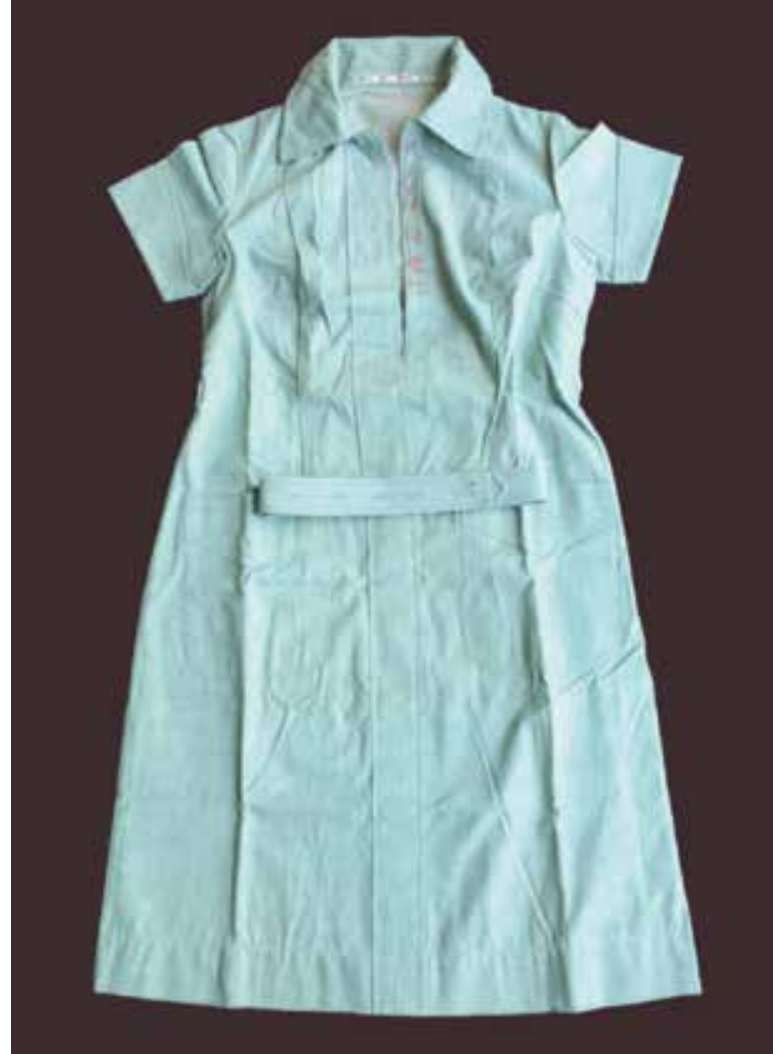

FIG. Green cotton uniform worn by midwives in government service in the 1970s to the 1990s. Kindly donated to the Hong Kong Museum of Medical Sciences by Ms Miu-ling Chan
Gazette, Ms Ho registered to become a midwife in 1969. Different from simpler garments worn in hospitals, there are two deep pockets on the front of the midwife's uniform, with a belt made from the same fabric. They were produced in Hong Kong at a time when the fabric and garment industries were still prosperous in the city.

Today, only one training course remains, under the management of Hospital Authority, for registered nurses to obtain a certificate in midwifery.
The course has been offered by Prince Wales Hospital since 1987, and >1500 modern midwives have been trained there. Because modern midwives must become registered nurses before training, they no longer need a different style of uniform. The unique green uniforms finally became obsolete and consigned to memory. Nevertheless, these uniforms represent a proud page of professionalism and sisterhood among those who devoted their lives to the most "productive" time in Hong Kong's history.

\section{References}

1. Hong Kong Legislative Council. Report of the Meeting, 1st September 1910: Midwives Ordinance. Hong Kong Hansard; 1 September 1910: 82-4.

2. Chan-Yeung MM. A Medical History of Hong Kong: 1842-1941. Hong Kong: The Chinese University of Hong Kong Press; 2018.

3. George J. The lady doctor's "Warm Welcome": Dr Alice Sibree and the early years of Hong Kong's maternity service 1903-1909. Journal of the Hong Kong Branch of the Royal Asiatic Society 1993;33:81-109.

4. Chow AW. Metamorphosis of Hong Kong midwifery. Hong Kong J Gynaecol Obstet Midwifery 2000;1:72-80.

5. Wanpo fined 25 dollars. Chinese Mail, 1927-09-22.

6. Practice of Wanpo. The Kung Sheung Daily News, 1936-11-05.

7. Wanpo. The Kung Sheung Daily News, 1936-08-07.

8. Census and Statistics Department, Hong Kong SAR Government. A Graphic Guide on Hong Kong's Development (1967-2007). Hong Kong SAR Government; 2007. 